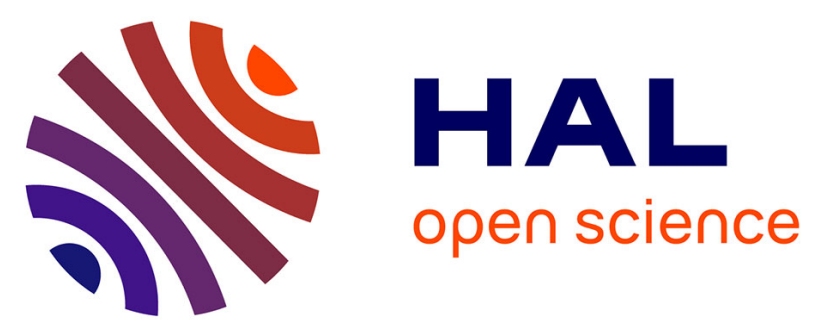

\title{
Analysis of dynamic mechanical properties of photochemically crosslinked poly(isobornylacrylate-co-isobutylacrylate) applying WLF and Havriliak-Negami models
}

Nouh Zeggai, Boumediene Dali Youcef, Frédéric Dubois, Tewfik Bouchaour, Philippe Supiot, Lamia Bedjaoui, Ulrich Maschke

\section{To cite this version:}

Nouh Zeggai, Boumediene Dali Youcef, Frédéric Dubois, Tewfik Bouchaour, Philippe Supiot, et al.. Analysis of dynamic mechanical properties of photochemically crosslinked poly(isobornylacrylate-coisobutylacrylate) applying WLF and Havriliak-Negami models. Polymer Testing, 2018, Polymer Testing, 72, pp.432-438. 10.1016/j.polymertesting.2018.10.038 . hal-02379713

\section{HAL Id: hal-02379713 \\ https://hal.univ-lille.fr/hal-02379713}

Submitted on 15 Oct 2020

HAL is a multi-disciplinary open access archive for the deposit and dissemination of scientific research documents, whether they are published or not. The documents may come from teaching and research institutions in France or abroad, or from public or private research centers.
L'archive ouverte pluridisciplinaire HAL, est destinée au dépôt et à la diffusion de documents scientifiques de niveau recherche, publiés ou non, émanant des établissements d'enseignement et de recherche français ou étrangers, des laboratoires publics ou privés. 
Analysis of dynamic mechanical properties of photochemically crosslinked poly(isobornylacrylate-co-isobutylacrylate) applying WLF and Havriliak-Negami models

Nouh Zeggai ${ }^{\text {a,b }}$, Boumediene Dali Youcef ${ }^{\mathrm{b}}$, Frédéric Dubois ${ }^{\mathrm{c}}$, Tewfik Bouchaour ${ }^{\mathrm{b}}$, Philippe Supiot ${ }^{\mathrm{d}}$, Lamia Bedjaoui ${ }^{\mathrm{b}}$, and Ulrich Maschke*,a

${ }^{\text {a }}$ Unité Matériaux et Transformations (UMET), UMR CNRS Nº207, Bâtiment C6, Université de Lille - Sciences et Technologies, 59655 Villeneuve d'Ascq Cedex, France

${ }^{\mathrm{b}}$ Laboratoire de Recherche sur les Macromolécules (LRM), Faculté des Sciences, Université Aboubakr Belkaïd de Tlemcen, 13000 Tlemcen, Algeria

${ }^{\mathrm{c}}$ Unité de Dynamique et Structure des Matériaux Moléculaires (UDSMM), Université du Littoral - Côte d'Opale (ULCO), 62228 Calais Cedex, France

d IEMN-P2M group, UMR CNRS N8520, Université de Lille - Sciences et Technologies, 59655 Villeneuve d'Ascq Cedex, France

Fax : 0033320436591 ; e-mail : ulrich.maschke@univ-lille1.fr

Declarations of interest: none 


\begin{abstract}
Chemically crosslinked poly (isobornylacrylate-co-isobutylacrylate) was elaborated by radical photo-copolymerization of isobornylacrylate and isobutylacrylate monomers in a 4:1 mass ratio, by adding a crosslinking agent at low concentration. The obtained copolymer was characterized by Fourier transform infrared spectroscopy for structural analysis, by differential scanning calorimetry for the determination of the glass transition temperature, and by thermogravimetric analysis to investigate thermal degradation effects. Storage modulus, dissipation modulus and tan delta were evaluated by dynamic mechanical analysis and modeled using different physical approaches such as the time-temperature superposition principle and the Havriliak-Negami model. The Cole-Cole curve was fitted with the Havriliak-Negami model yielding five parameters which were used to calculate the dynamic mechanical properties of the copolymer over a large frequency range from $1.03 \times 10^{-4} \mathrm{~Hz}$ to $7.58 \times 10^{7} \mathrm{~Hz}$. Calculated elastic and dissipative moduli agree well with the experimental data.
\end{abstract}

Keywords: copolymer; dynamic mechanical analysis; time-temperature superposition principle; Cole Cole; Havriliak-Negami; WLF. 


\section{Introduction}

Current technology requires high-performance polymeric materials with highly specialized functions; these materials are generally composed of multiple types of macromolecules such as copolymers, terpolymers,... [1-5]. The properties of a given homopolymer can indeed be improved by combining several polymers: it is therefore possible to adapt and optimize its physical state and properties that depend on the chemical nature and the number of monomeric units involved.

Poly(isobornylacrylate) (poly(IBOA)) has received particular attention recently due to its interesting physical properties: high glass transition temperature of conventional poly(IBOA) $\left(\mathrm{T}_{\mathrm{g}}=94^{\circ} \mathrm{C}\right)$ [6], lightness, excellent light transmission, strong chemical resistance, good insulating properties, and low cost manufacturing. These characteristics give the poly(IBOA) numerous possibilities of applications in various fields. Among others, Poly(IBOA) and its copolymers have been proposed as construction material for microfluidic applications $[\mathbf{7 , 8}]$, as innovative porous organic material [9], as polymer adhesive exhibiting increased peal strength [10], and for shape-memory polymers [11]. In particular, IBOA can be used in Ultraviolet (UV)/Electron Beam curing formulations to provide coatings and inks with good hardness, resiliency, flexibility and impact resistance [12].

Because of its limited thermomechanical properties for many applications, especially at subambient temperatures, the development of poly(IBOA) based copolymers was proven to be more advantageous compared to the use of the homopolymer. Relaxation processes of poly(IBOA) and poly(isobornylmethacrylate) (poly(isoBOMA)) based systems have been studied using different analytical methods (dielectric spectroscopy, NMR, dynamic mechanical analysis (DMA)) [13-16]. Segmental dynamics of poly(isoBOMA) and a copolymer with poly(methylmethacrylate) (poly(MMA)) were investigated in the glass transition temperature region by Alvarez et al. by spectroscopic methods [13]. Khandelwal et 
al. studied the microstructure of the poly (isobutylacrylate-co-MMA) copolymer (poly (IsoBA-co-MMA)) by nuclear magnetic resonance (NMR) $[\mathbf{1 4 , 1 5 ]}$. So far, however, only few studies have been performed on the mechanical properties of poly(IBOA) and its copolymers. Jakubowski et al. [16] reported on thermomechanical properties and the correlation between structure and properties of different copolymers formed by IBOA and n-butyl acrylate (nBA). In this work, the choice of the co-monomer was focused on IsoBA, in particular because of the different thermal and structural properties (Fig. 1) presented by IBOA $\left(\mathrm{T}_{\mathrm{g}}(\mathrm{IBOA})=94^{\circ} \mathrm{C}\right)$ and IsoBA $\left(\mathrm{T}_{\mathrm{g}}(\mathrm{IsoBA})=-33^{\circ} \mathrm{C}\right)$. To the best of our knowledge this type of poly(IBOA-coIsoBA) copolymer has not yet been studied and provides great potential for various applications.

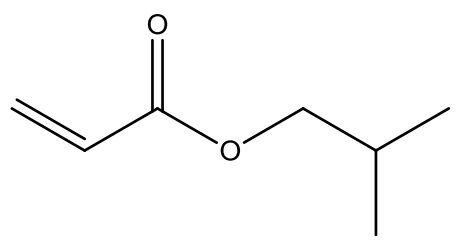

Isobutyl acrylate

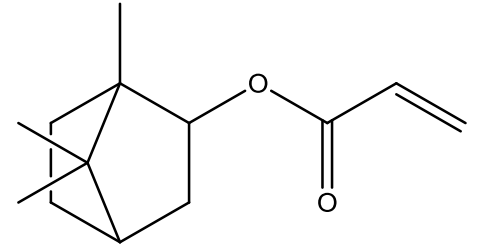

isobornyl acrylate

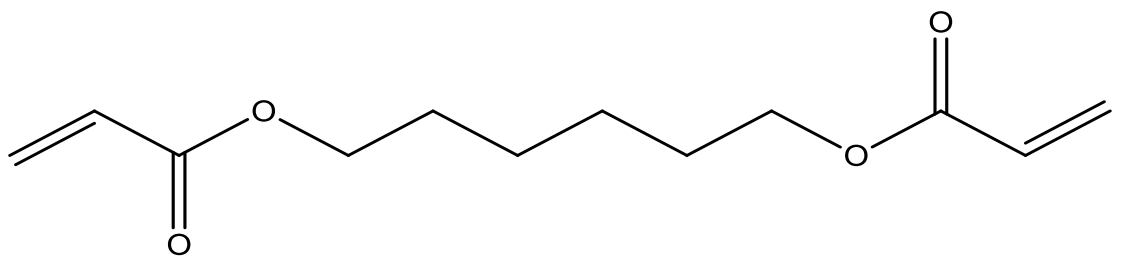

1,6-Hexanediol diacrylate

Fig. 1. Chemical structures of the monomers isobutyl acrylate (IsoBA), isobornyl acrylate (IBOA) and 1.6-hexanediol diacrylate (HDDA).

For a better understanding of mechanical behavior and relaxations for industrial applications, the dynamic mechanical properties of a chemically crosslinked poly(IBOA-co-IsoBA) copolymer were investigated using DMA. This method is considered as one of the most effective for studying the structural and mechanical relaxation of polymeric materials [17-20] 
In literature, a large number of studies have been reported on the analysis of experimental results obtained by DMA, applying diverse models such as: Cole and Cole [21], Davidson and Cole [22], Havriliak-Negami (HN) [23], and Kohlrausch-Williams-Watts (KWW) [24]. The relationship between KWW and $\mathrm{HN}$ models has been described in [25].

In this work particular attention was paid to the application of the HN model to rationalize the mechanical dynamic behavior of the elaborated poly(IBOA-co-IsoBA) copolymer. Further characterization was performed by Fourier transform infrared spectroscopy (FTIR), differential scanning calorimetry (DSC) and thermogravimetric analysis (TGA).

\section{Experimental}

\subsection{Sample preparation}

The monomers IsoBA, IBOA, and the crosslinking agent 1,6 hexanedioldiacrylate (HDDA) were provided by Sigma-Aldrich (France). The photoinitiator used was Darocur 1173 (2hydroxy-2-methyl-1-phenyl-propan-1-one).

The monomer mixtures IBOA/HDDA/Darocur 1173, IsoBA/HDDA/Darocur 1173 and IBOA/IsoBA/HDDA/Darocur 1173 (IBOA/IsoBA mass ratio=4/1) were prepared using mass concentrations of 0.5 weight $\%$ (wt- $\%$ ) and 2 wt- $\%$ of HDDA and Darocur 1173, respectively. The monomeric mixtures were then arranged in different forms according to the characterization method (thin films less than $10 \mu \mathrm{m}$ thick between a $\mathrm{NaCl}$ plate and a poly(ethyleneterephthalate) film for FTIR measurements, in a cylindrical Teflon mold for the other techniques), then exposed to radiation under inert atmosphere of a UV source (Philips TL08) of wavelength $\lambda=350 \mathrm{~nm}$ and intensity $\mathrm{I}_{0}=1.5 \mathrm{~mW} / \mathrm{cm}^{2}$. With the exception of FTIR analysis, the sample exposure time was set at $35 \mathrm{~min}$ to achieve complete conversion of all precursor monomers. The resulting polymers, called poly(IBOA), poly(IsoBA) and poly(IBOA-co-IsoBA), were rigid and optically transparent at ambient temperature. 


\subsection{Infrared spectroscopy}

FTIR spectra were recorded in transmission mode using a Perkin Elmer Frontier model with a spectral resolution of $4 \mathrm{~cm}^{-1}$ applying 16 scans. Cumulated doses were administered for UVcuring, the interval of time between the end of exposure and the infrared analysis was kept constant for around one minute. The experiments were repeated three times to check the reproducibility of the results.

\subsection{Differential Scanning Calorimetry}

The thermal properties of the elaborated polymers, such as glass transition temperatures, were determined by means of a DSC 8000 instrument (PerkinElmer). This instrument was calibrated using indium and zinc as standards (heating rate $10^{\circ} \mathrm{C} / \mathrm{min}$ ). The samples were prepared by introducing 8 to $10 \mathrm{mg}$ of the polymers into aluminum pans. Heating and cooling rates of $10^{\circ} \mathrm{C} / \mathrm{min}$ were applied in the temperature range from $-72^{\circ} \mathrm{C}$ to $+100^{\circ} \mathrm{C}$ under nitrogen flow. The program consists of cooling the sample first, followed by three cycles of heating and cooling to take into account any thermal events related to the sample preparation history. Only the thermograms of the second heating cycle were taken into account. The glass transition temperatures were determined from the points of inflection of the thermograms.

\subsection{Thermogravimetric analysis}

Thermogravimetric (TGA) and differential thermal (DTA) analysis were performed using a Pyris 1 TGA device (Perkin Elmer) with a resolution of $1 \mu \mathrm{g}$. The analysis of the sample was carried out under nitrogen atmosphere, applying a flow rate of $20 \mathrm{~mL} / \mathrm{min}$. The samples, with an average mass of $8 \mathrm{mg}$, were prepared in quartz crucibles and heated from $50^{\circ} \mathrm{C}$ to $900^{\circ} \mathrm{C}$ with a speed of $10^{\circ} \mathrm{C} / \mathrm{min}$. 


\subsection{Dynamic mechanical analysis}

Dynamic mechanical measurements were carried out by means of a DMA 8000 (Perkin Elmer) spectrometer in frequency sweep mode from $0.1 \mathrm{~Hz}$ to $50 \mathrm{~Hz}$ at temperatures between $25^{\circ} \mathrm{C}$ and $90^{\circ} \mathrm{C}$. A heating rate of $5^{\circ} \mathrm{C} / \mathrm{min}$ was applied for each temperature variation followed by isothermal steps during $10 \mathrm{~min}$ to reach thermodynamic equilibrium before starting the frequency sweep mode. The overall measuring period was estimated at $72 \mathrm{~s}$ for each temperature $\left(25^{\circ} \mathrm{C}, 30^{\circ} \mathrm{C}, 35^{\circ} \mathrm{C}, \ldots \ldots, 90^{\circ} \mathrm{C}\right)$. The polymer samples were in the form of rectangular parallelepipeds with dimensions of $10 \mathrm{~mm} \times 6 \mathrm{~mm} \times 2 \mathrm{~mm}$. Uniaxial tensile deformation was applied under the condition of controlled deformation amplitude remaining in the range of a linear viscoelastic response. A special set-up designed for the investigated samples was used and the experiments were performed under dry nitrogen atmosphere.

\section{Results \& discussion}

\subsection{Structural analysis}

The infrared spectra corresponding to the kinetics of polymerization/crosslinking of the monomer mixture IBOA/IsoBA/HDDA are presented in the insert of Fig. 2. The bands located in particular at $810 \mathrm{~cm}^{-1}$ and $1637 \mathrm{~cm}^{-1}$ correspond to the acrylic double bonds $\mathrm{C}=\mathrm{C}$; those at $1735 \mathrm{~cm}^{-1}, 1300 \mathrm{~cm}^{-1}$ and $900 \mathrm{~cm}^{-1}$ are linked to the $\mathrm{C}=\mathrm{O}$ double bond and to the simple C-O and C-H bonds (Table 1). Changes of the absorbance of the band at $810 \mathrm{~cm}^{-1}$ $(\mathrm{C}=\mathrm{C})$ were considered to represent the evolution of photopolymerization reactions during UV irradiation (for details please see [26]). Fig. 2 also shows that an irradiation time of 35min makes it possible to obtain maximum conversion of the acrylic functions. In comparison with the kinetics of polymerization/crosslinking of the n-butyl acrylate monomer [27], the irradiation time necessary to reach a plateau of the conversion rate seems to be relatively important. High acrylic double bond conversions should be obtained to minimize undesired 
effects of unreacted or partially reacted monomers that may influence mechanical (storage modulus) and thermal properties (glass transition temperature).

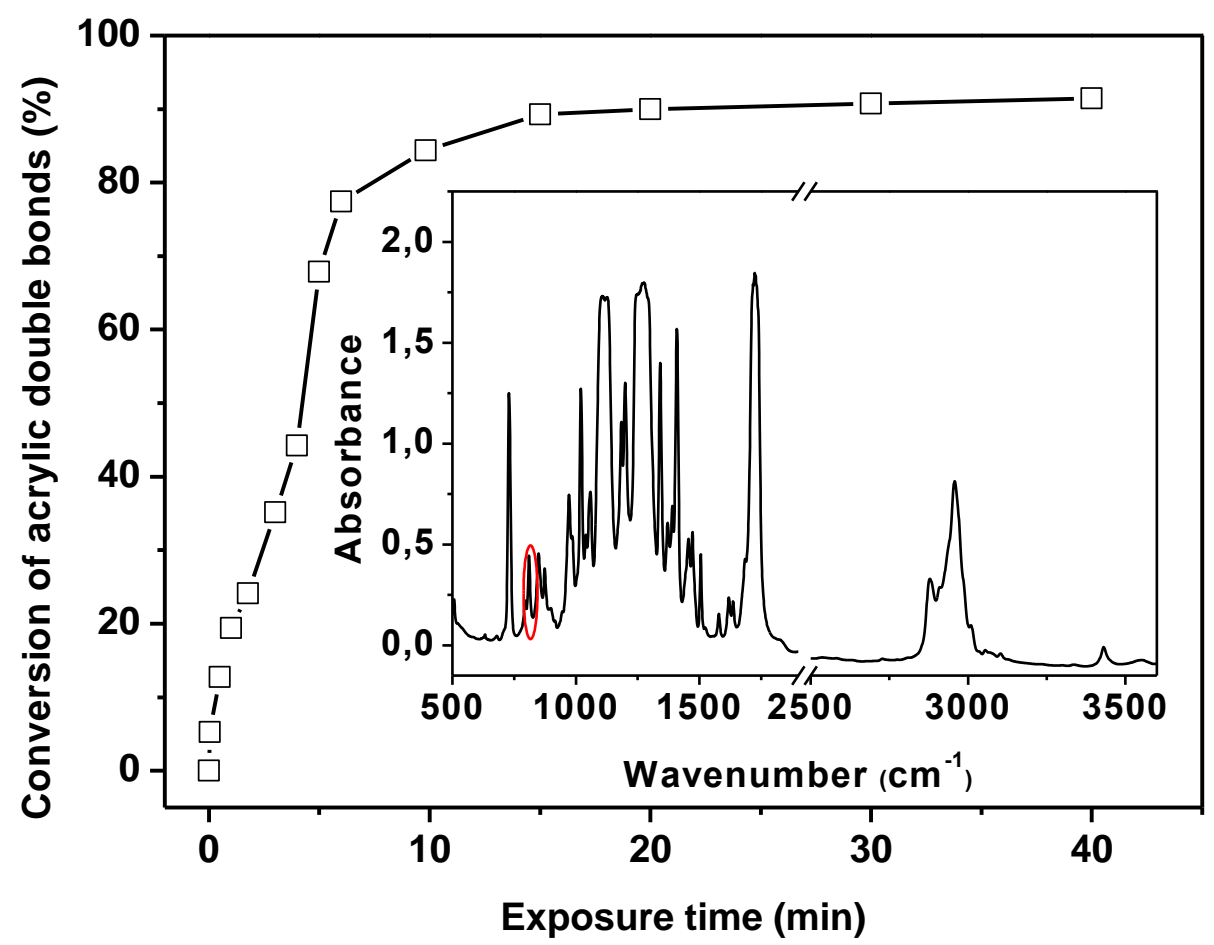

Fig. 2. Evolution of the conversion rate of acrylic functions as function of exposure time to UV irradiation of the precursor monomer mixture IBOA/IsoBA/HDDA/Darocur 1173. This curve was deduced from the decrease of the surface of the absorption band at $810 \mathrm{~cm}^{-1}(\mathrm{C}=\mathrm{C}$ bond) (insert) as function of the irradiation time.

\begin{tabular}{|c|c|l|}
\hline Wavenumber $\left(\mathbf{c m}^{-1}\right)$ & Designation & Description of the vibration \\
\hline 2956 & $v_{\text {asym }} \mathrm{CH}_{3}$ & Asymmetrical elongation of $\mathrm{CH}_{3}$ \\
\hline 2937 & $v_{\text {asym }} \mathrm{CH}_{2}$ & Asymmetrical elongation of $\mathrm{CH}_{2}$ \\
\hline 1735 & $v \mathrm{C}=\mathrm{O}$ & Elongation of $\mathrm{C}=\mathrm{O}$ \\
\hline 1466 & $\delta_{\text {asym }} \mathrm{CH}_{3}$ & Asymmetric deformation of $\mathrm{CH}_{3}$ \\
\hline 1387 & $\delta_{\text {sym }} \mathrm{CH}_{3}$ & Symmetrical deformation of $\mathrm{CH}_{3}$ \\
\hline 1272 & $v_{\text {asym }} \mathrm{CCO}$ et $v \mathrm{CO}$ & Elongation of $\mathrm{CO}$ and asymmetric of $\mathrm{CCO}$ \\
\hline 1177 & $v \mathrm{C}-\mathrm{C}$ & Elongation of the C-C skeleton, $\mathrm{CH}$ \\
\hline $1637-810$ & $v \mathrm{C}=\mathrm{C}$ & Elongation of acrylate \\
\hline
\end{tabular}

Table 1. Vibration bands of poly (IBOA-co-IsoBA). 


\subsection{Thermal properties}

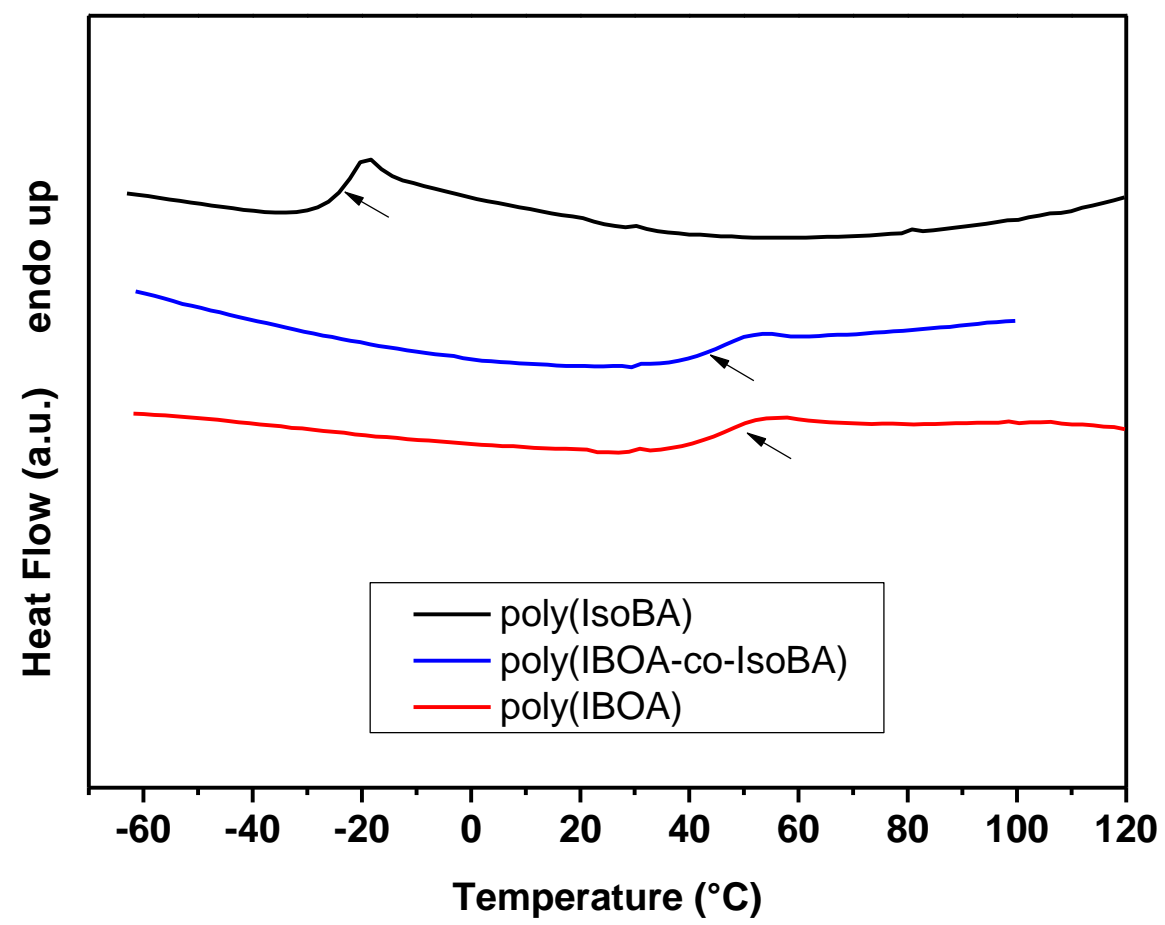

Fig. 3. Thermograms of the homopolymers: poly(IsoBA) and poly(IBOA), and of the copolymer poly (IBOA-co-IsoBA).

Thermograms of poly(IBOA), poly(IBOA-co-IsoBA), and poly(IsoBA) are gathered in Fig. 3 . The glass transition temperature $\mathrm{T}_{\mathrm{g}}$ of poly(IBOA-co-IsoBA) was determined at $45.2^{\circ} \mathrm{C}$ and is situated between those of the homopolymers poly(IsoBA) and poly(IBOA) : $\mathrm{T}_{\mathrm{g}}(\mathrm{IsoBA})=-$ $23.5^{\circ} \mathrm{C}$, and $\mathrm{T}_{\mathrm{g}}(\mathrm{IBOA})=46.3^{\circ} \mathrm{C}$. Like the two homopolymers, the copolymer presents a single glass transition temperature and shows no crystallinity effect; it is thus completely amorphous and its constituents form a single phase [28]. These observations (single glass transition temperature, amorphous character, absence of phase separation) were previously made by Jakubowski et al. [16] for poly(IBOA-co-nBA). Furthermore, for concentrations of IBOA and nBA respectively equal to $78 \mathrm{wt}-\%$ and $22 \mathrm{wt}-\%$, the glass transition temperature of this copolymer $\left(42^{\circ} \mathrm{C}\right)$, is in the same order of magnitude as that of poly(IBOA-co-IsoBA) 
$\left(45.2^{\circ} \mathrm{C}\right)$.
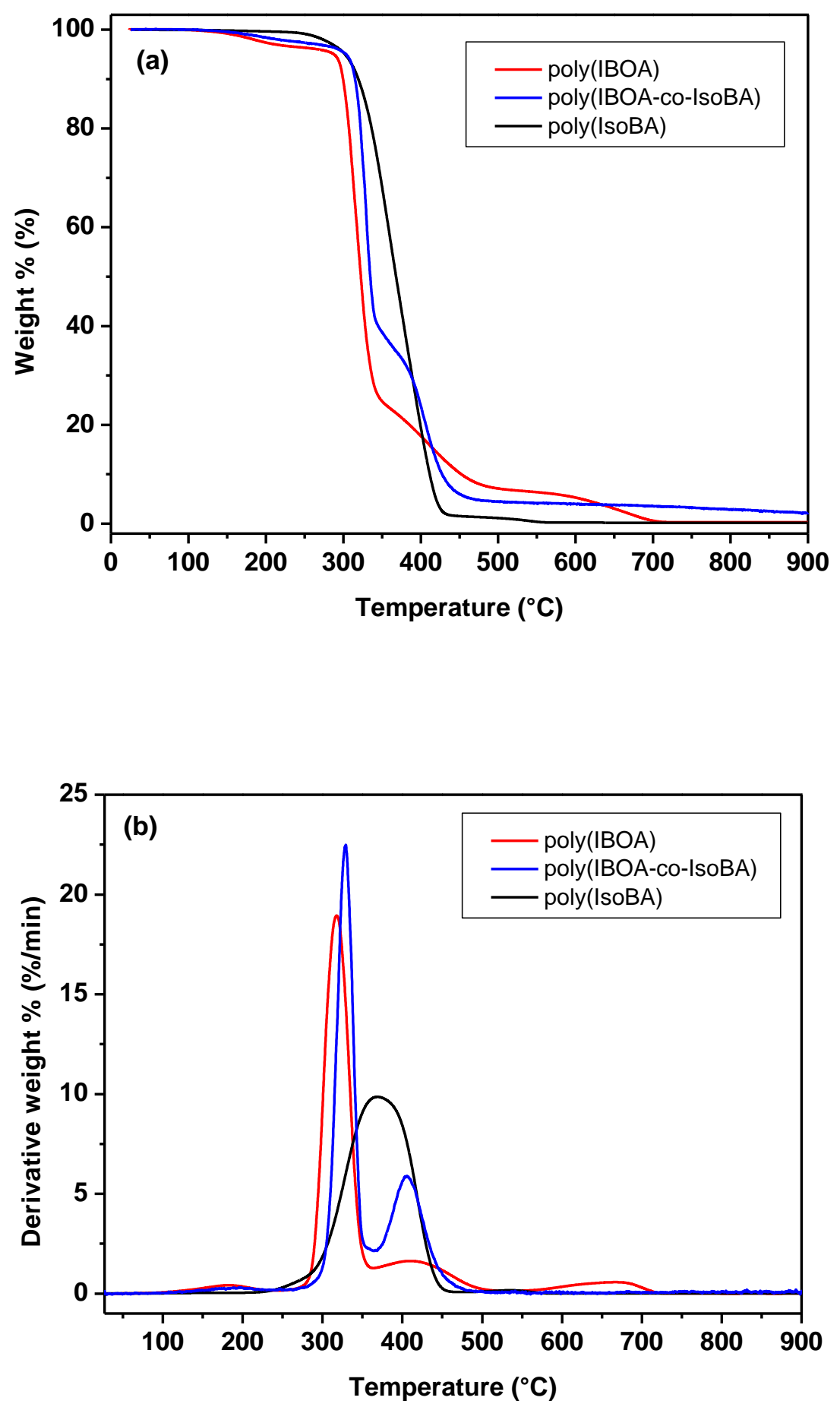

Fig. 4. (a) Evolution of the remaining weight percentage of poly(IsoBA), poly(IBOA) and poly(IBOA-co-IsoBA) as function of temperature. (b) Derivative weight percentage vs temperature. 
The results of the thermogravimetric analysis of the polymers are shown in Fig. 4. Poly (IBOA-co-IsoBA) and poly(IBOA) begin to lose weight at temperatures above $170^{\circ} \mathrm{C}$; since poly(IBOA) exhibits relatively low thermal stability [29]. On the other hand, poly(IsoBA) remains thermally stable up to $259^{\circ} \mathrm{C}$. Thermal degradation of poly(IsoBA) took place as a single process, but that of poly(IBOA-co-IsoBA) and poly(IBOA) occurred in two stages. The dual TGA transition can be related to the chemical structure of the pendant alkyl group $[\mathbf{2 9}, \mathbf{3 0}]$. Ors and La Perriere [29] proposed a free radical degradation mechanism yielding in the case of poly(IBOA) to the formation of mainly camphene and a nortricyclic derivative through thermal rearrangements. This two-step degradation has already been observed for poly(cycloalkylmethacrylates) [31] and for poly(IBOMA-co-nBA) [32]; moreover, the characteristic decomposition temperatures of the latter material (between $290^{\circ} \mathrm{C}$ and $375^{\circ} \mathrm{C}$ and between $375^{\circ} \mathrm{C}$ and $500^{\circ} \mathrm{C}$ ) were found to be close to those observed for poly(IBOA-coIsoBA).

\subsection{Dynamic mechanical analysis}

The results of the dynamic mechanical analysis of poly(IBOA-co-IsoBA) are shown in Fig. 5. The evolution of the storage modulus E' with temperature is typical of an amorphous polymer (Fig. 5a): this parameter shows a decrease of $1.17 \times 10^{9} \mathrm{~Pa}$ at $20^{\circ} \mathrm{C}$ to a very low value of $2.37 \times 10^{5} \mathrm{~Pa}$ at $90^{\circ} \mathrm{C}$. This variation of $\mathrm{E}^{\prime}$ is related to the mechanical relaxation associated with the reorganization of the metastable amorphous structure, when the material passes from the glassy solid to a viscous liquid state by approaching the glass transition temperature $T_{g}$. This phenomenon is well-known for polymeric matrices [19,33-34], and has been reported by Ware et al. for poly(IBOA-co-methylacrylate) [35]. The shape of the loss modulus curve of poly (IBOA-co-IsoBA) was found to be similar to that of $\tan \delta$, with the exception that $\tan \delta$ 
reaches its maximum at a higher temperature than the loss modulus (Figs. 5b and $\mathbf{5 c}$ ).
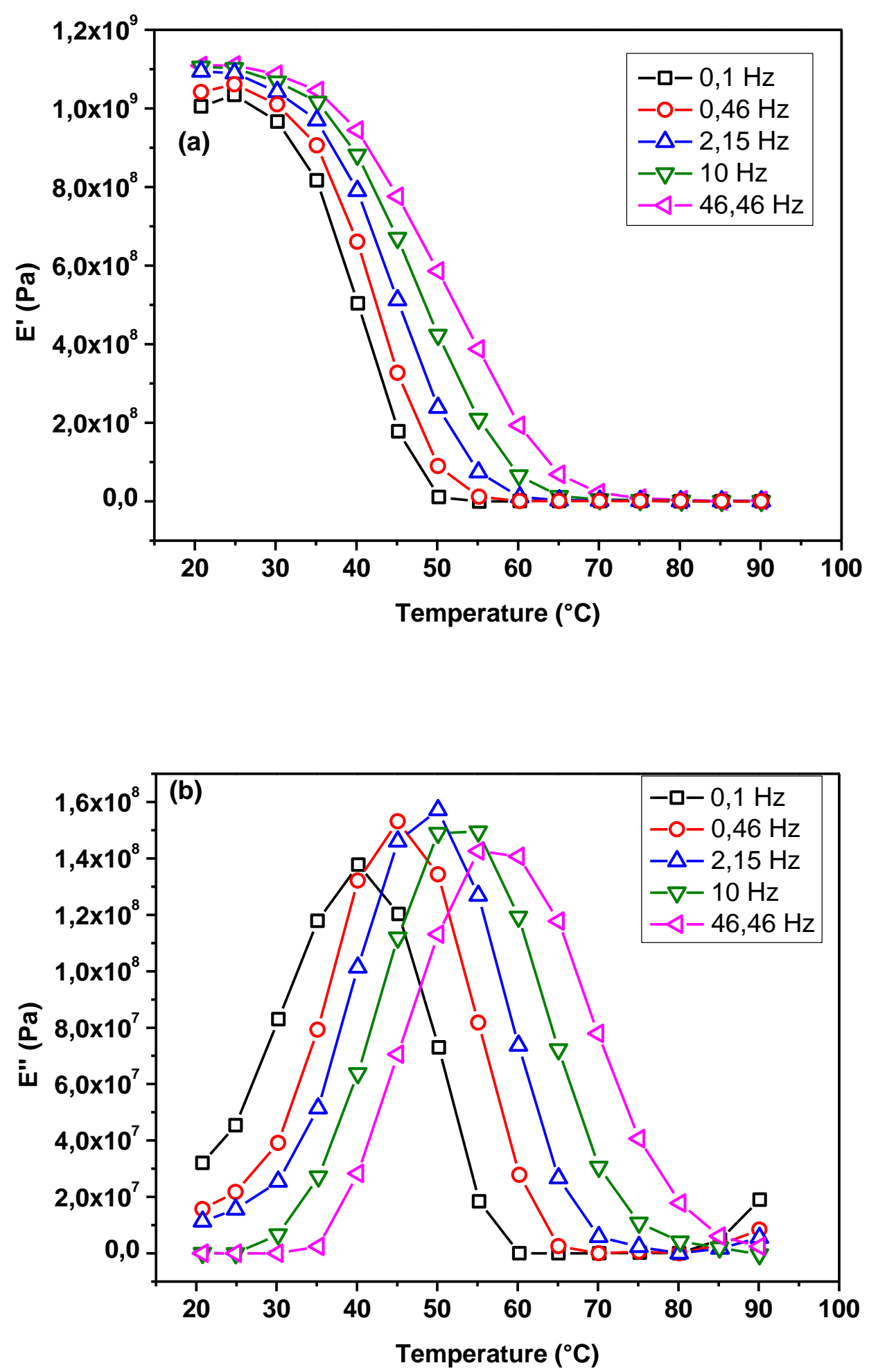


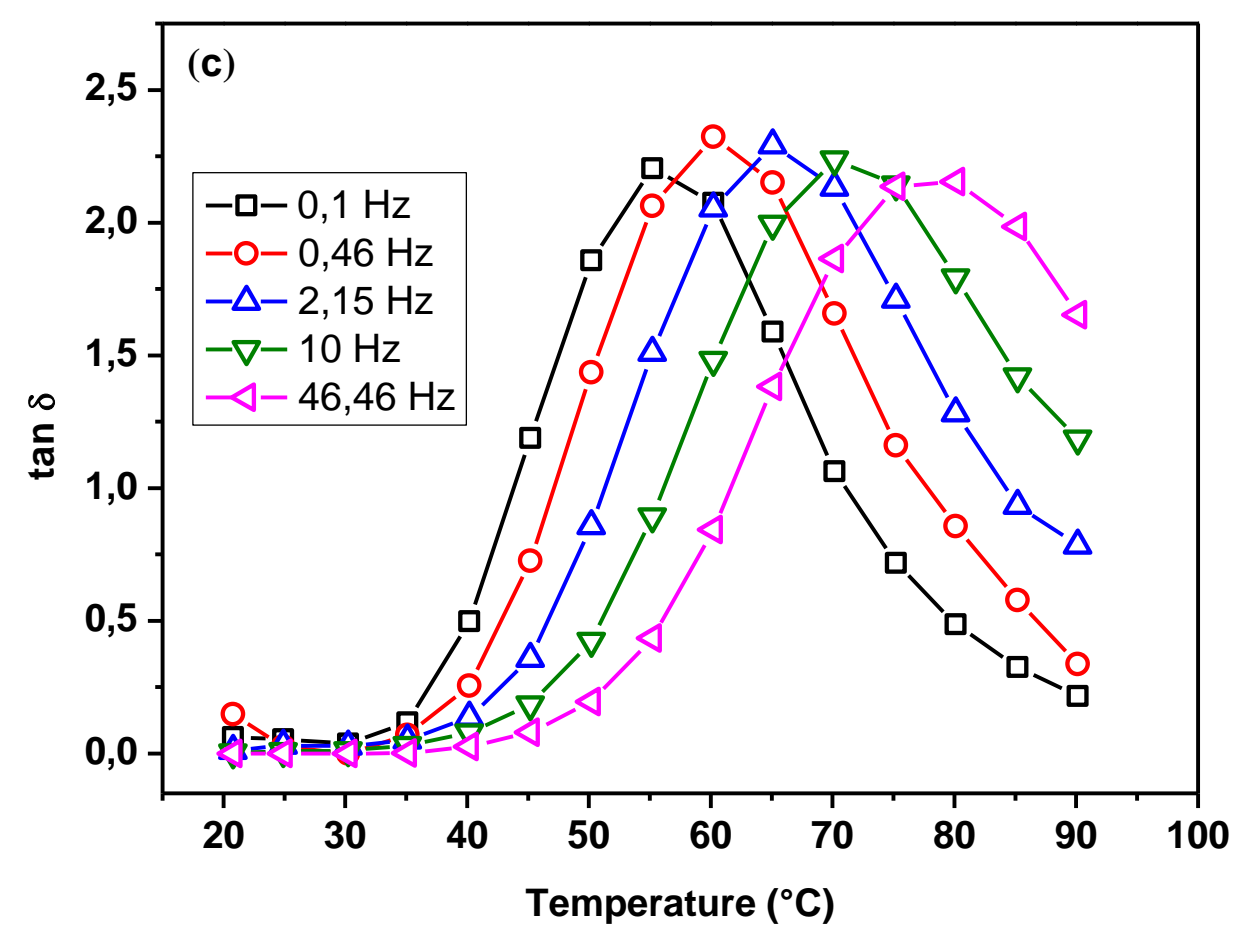

Fig. 5. Evolution as function of temperature (a) of the storage modulus E', (b) of the loss modulus $\mathrm{E}^{\prime \prime}$ and (c) of the loss factor $\tan \delta$ of poly(IBOA-co-IsoBA) for different measurement frequencies.

The evolution of the loss modulus E" as function of temperature of the poly (IBOA-co-IsoBA) copolymer was found to be similar to that of its $\tan \delta$ (Figs. 5b and 5c). This confirms the results from DSC analysis and the monophasic character of the copolymer. The temperature corresponding to the maximum of $\tan \delta$ increases with the measurement frequency and can be associated with $\mathrm{T}_{\mathrm{g}}$ (Table 2). Moreover, $\mathrm{T}_{\mathrm{g}}$ values obtained by DMA were found to be higher than those obtained by the DSC technique. The latter corresponds to the initial drop of the storage modulus $\left(\mathrm{E}^{\prime}\right)$ at the beginning of the glass transition, while $\mathrm{T}_{\mathrm{g}}$ values from DMA are more closely linked to the median transition point or the point of inflection of the decreasing curve of the storage modulus (E'). 


\begin{tabular}{|c|c|c|}
\hline $\mathbf{f}(\mathbf{H z})$ & $\mathbf{T}_{\mathbf{g}}\left({ }^{\circ} \mathbf{C}\right)$ & $\tan \boldsymbol{\delta}\left(\mathbf{T}=\mathbf{T}_{\mathbf{g}}\right)$ \\
\hline 0.1 & 55.2 & 2.20 \\
\hline 0.46 & 60.2 & 2.32 \\
\hline 2.15 & 65.1 & 2.20 \\
\hline 10 & 70.1 & 2.23 \\
\hline 46.46 & 75.1 & 2.15 \\
\hline
\end{tabular}

Table 2. Glass transition temperatures $\left(\mathrm{T}_{\mathrm{g}}\right)$ of poly(IBOA-co-IsoBA) deduced from DMA as function of the measurement frequency $f$, and loss factor $\tan \delta$ for $\mathrm{T}=\mathrm{T}_{\mathrm{g}}$.

Samples of poly(IBOA-co-IsoBA) were subjected to frequency sweeps at different temperatures and a master curve was constructed to verify the principle of time-temperature superposition on mechanical properties from the storage modulus.

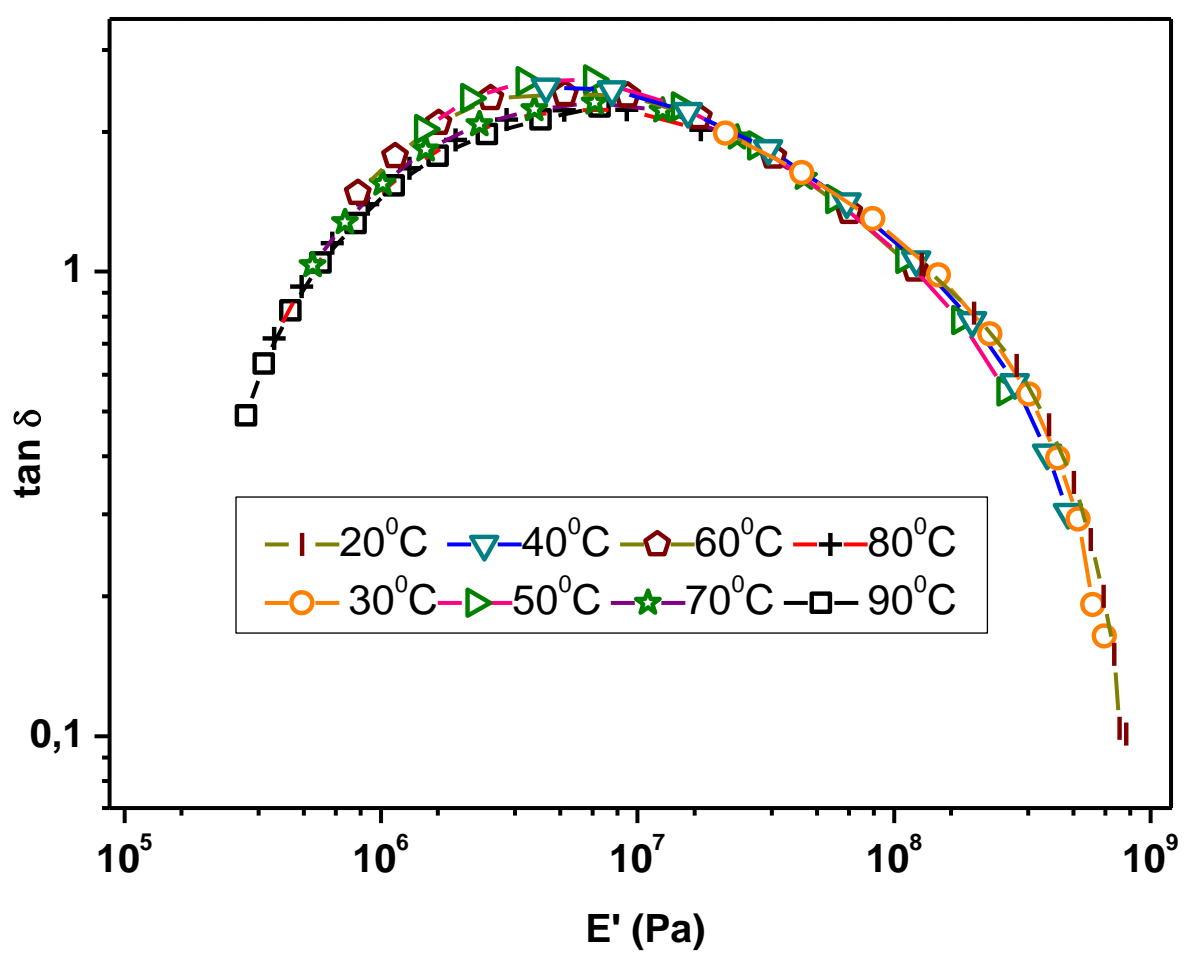

Fig. 6. Variation of the loss factor tan $\delta$ of poly(IBOA-co-IsoBA) as function of its storage modulus E' ("Wicket plot" representation). 
The "Wicket-plot" is shown in Fig. 6, which assesses whether the data are suitable for analysis using the empirical Williams-Landel-Ferry (WLF) relationship [36]. It is clearly seen that the curve of Fig. $\mathbf{6}$ is almost entirely symmetrical and there is no anomaly, which makes it possible to apply the principle of time-temperature superposition. Fig. 7 shows the storage modulus E' as function of frequency in logarithmic scale. It can be seen that $\mathrm{E}^{\prime}$ increases as temperature decreases and frequency increases. This evolution is simply due to an increase in molecular mobility when the temperature increases or when the frequency decreases. The master curve can be determined by the principle of time-temperature superposition using the WLF equation (1) to evaluate the shift factor $\mathrm{A}_{\mathrm{T}}[\mathbf{3 6}]$.

$\ln (A)_{T}=\frac{-C_{1}\left(T-T_{0}\right)}{C_{2}+T-T_{0}}$

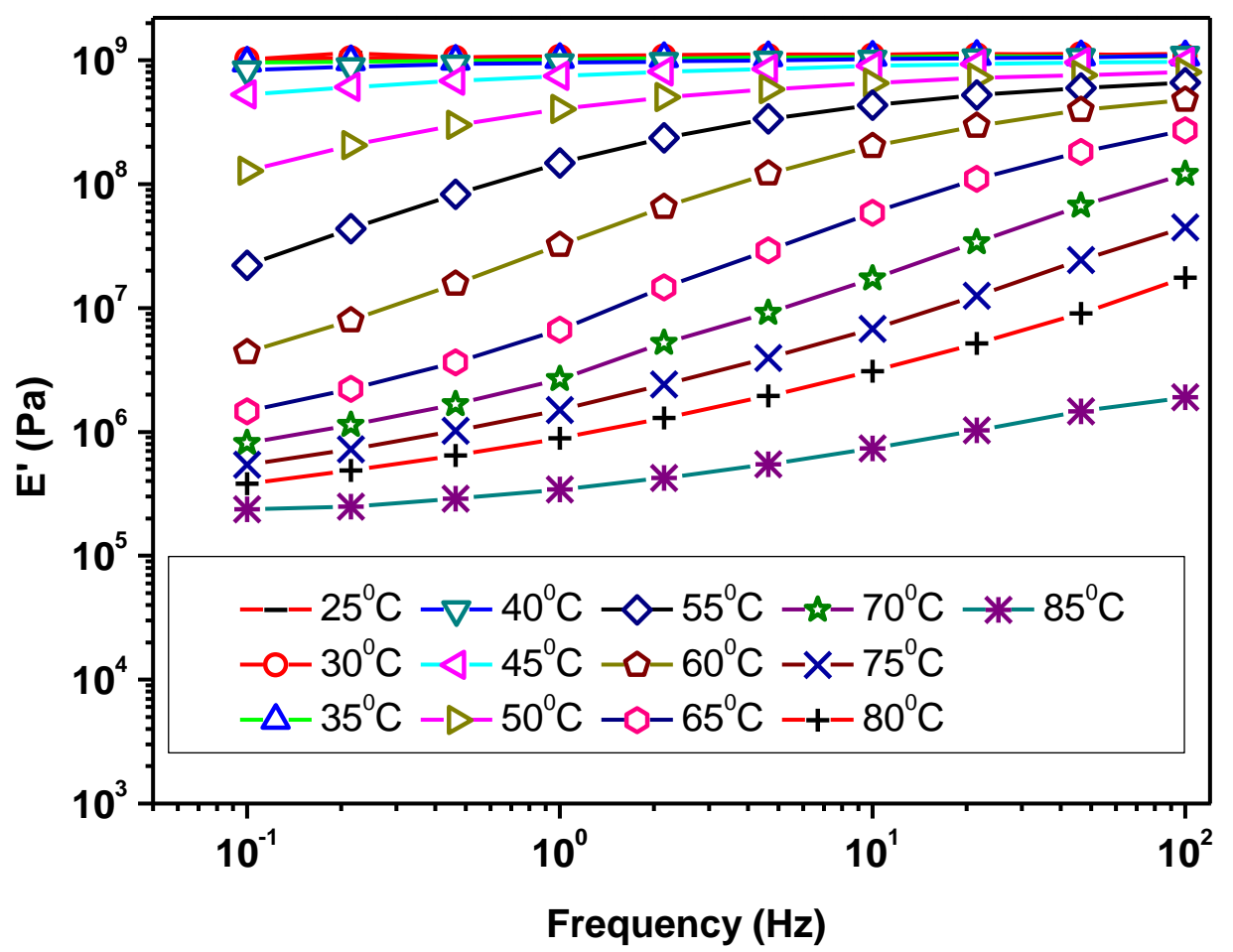

Fig. 7. Frequency dependence of the storage modulus E' of poly (IBOA-co-IsoBA) at different temperatures. 
The values of $\mathrm{C}_{1}$ and $\mathrm{C}_{2}$ were determined as 17.4 and 51.6, respectively, and represent standard values for polymers in general, $\mathrm{T}_{0}$ stands for the reference temperature on which the other curves agree; which was chosen as $60^{\circ} \mathrm{C}$. The choice of this reference temperature allowed to obtain the largest width of the frequency interval for the application of the WLF model. The reference temperature is typically situated between the glass transition temperature and $\mathrm{T}_{\mathrm{g}}+100^{\circ} \mathrm{C}$ since this interval is valid to apply WLF equation. Fig. 8 shows the final master curve. The data of the storage module (E') do not seem to change significantly (on this logarithmic scale Y) in the frequency range between $100 \mathrm{~Hz}$ and $10 \mathrm{MHz}$. This module is situated between $5.44 \times 10^{8} \mathrm{~Pa}$ at $100 \mathrm{~Hz}$ and $1.13 \times 10^{9} \mathrm{~Pa}$ at $10 \mathrm{MHz}$.

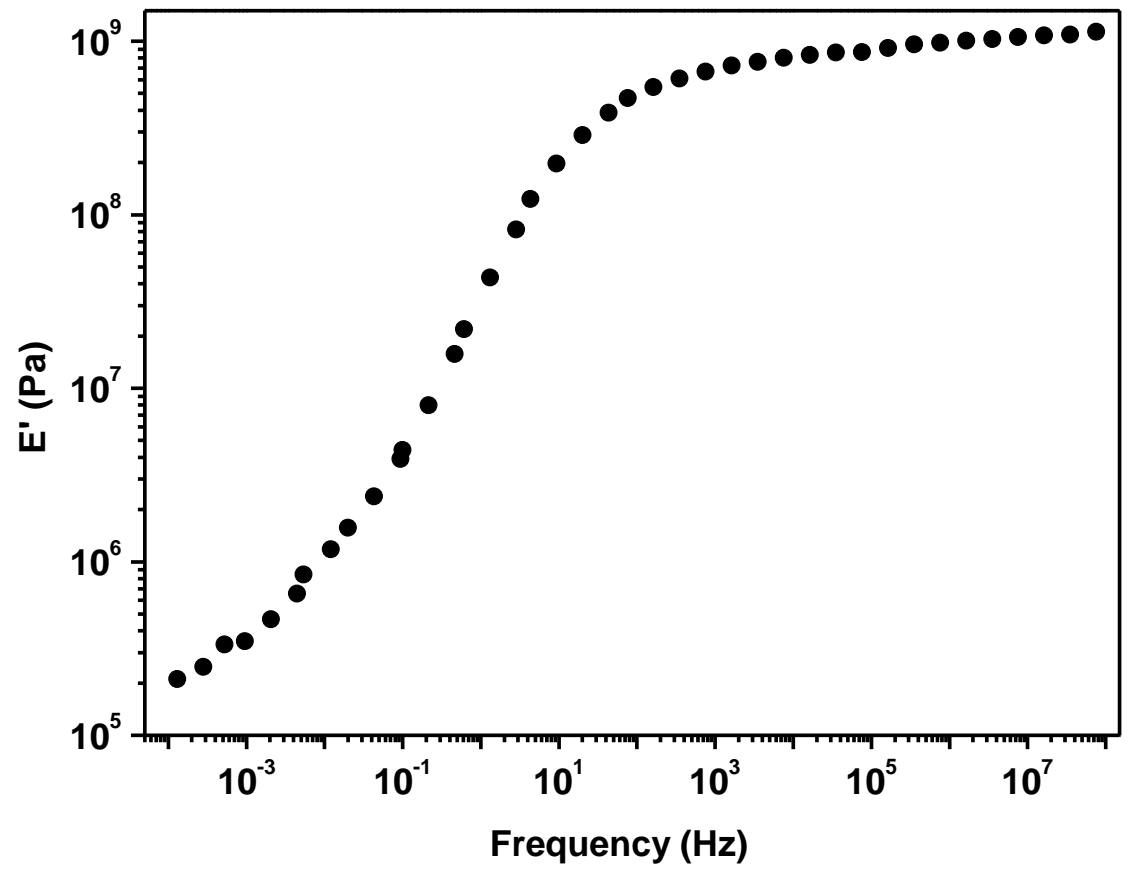

Fig. 8. Master curve of poly (IBOA-co-IsoBA).

\subsection{Prediction of dynamic mechanical properties}

The relaxation of the copolymer, observed previously (Fig. 5), is also highlighted on the 
evolution curves of the storage (E') and loss (E") moduli as a function of the measurement frequency for different temperatures (Fig. 9). These spectra were modeled using the Havriliak-Negami relation (Equation (2)).

$E^{*}(\omega)=E_{\infty}+\frac{E_{0}-E_{\infty}}{\left[1+(i \omega \tau)^{\alpha}\right]^{\beta}}$

where $E^{*}(\omega)=E^{\prime}(\omega)+i E^{\prime \prime}(\omega)$

$E_{0}$ and $E_{\infty}$ represent the storage moduli of the copolymer at low and high frequency, respectively, $\omega=2 \pi f, \tau$ is the relaxation time, and $i=\sqrt{-1}$. The two adjustable parameters $\alpha$ and $\beta$ are respectively related to the amplitude and dissymmetry of the distribution of the relaxation times $(0<\alpha, \beta \leq 1)$. The results of the optimization of the mechanical spectra of poly (IBOA-co-IsoBA) (for $\mathrm{T}=40^{\circ} \mathrm{C}, 45^{\circ} \mathrm{C}, 50^{\circ} \mathrm{C}$ ), carried out using the $\mathrm{HN}$ model and the $\mathrm{R}$ software, are reported in Table 3 .

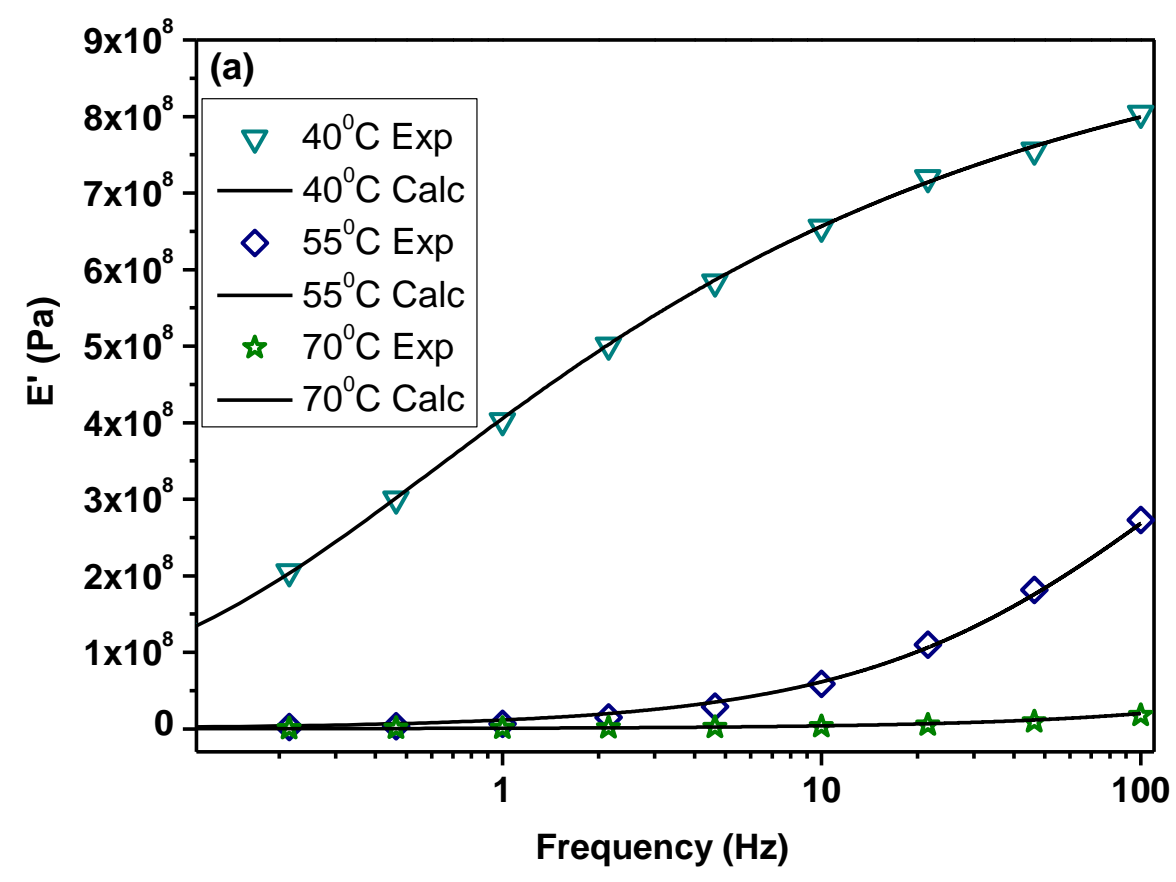




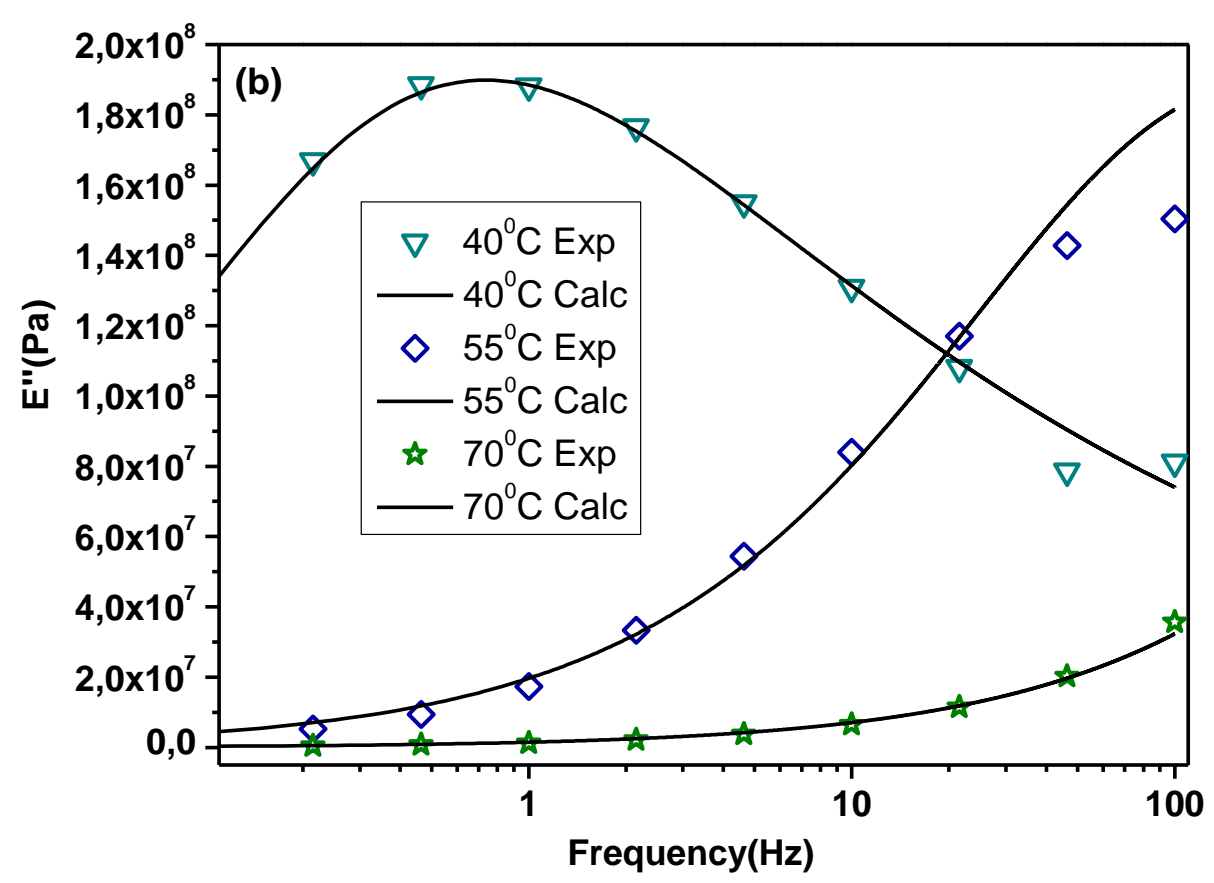

Fig. 9. Mechanical spectra of poly (IBOA-co-IsoBA). The experimental results were modeled using the Havriliak-Negami model.

\begin{tabular}{|l|l|l|l|l|l|l|}
\hline $\mathbf{T}\left({ }^{\circ} \mathbf{C}\right)$ & $\boldsymbol{\alpha}$ & $\boldsymbol{\beta}$ & $\mathbf{E}_{\mathbf{0}}(\mathbf{P a})$ & $\mathbf{E}_{\infty}(\mathbf{P a})$ & $\boldsymbol{\tau}(\mathbf{s})$ & $\mathbf{r m s}$ \\
\hline 40 & 0.685 & 0.399 & 0 & $9.63 \times 10^{8}$ & 0.731 & $4.04 \times 10^{6}$ \\
\hline 45 & 0.722 & 0.415 & 0 & $8.68 \times 10^{8}$ & 0.109 & $4.45 \times 10^{6}$ \\
\hline 50 & 0.747 & 0.402 & 0 & $7.92 \times 10^{8}$ & 0.022 & $2.18 \times 10^{6}$ \\
\hline
\end{tabular}

Table 3. Results of optimization of the mechanical spectra of poly(IBOA-co-IsoBA), carried out using the Havriliak-Negami model.

The quality of the optimization is given by the value of the mean squared error (roortmeansquare: rms) (Equation (4):

$r m s=\sqrt{\frac{\sum_{k=1}^{N}\left|E_{\text {exp }, k}^{\prime}-E_{c a l c, k}^{\prime}\right|^{2}+\sum_{k=1}^{N}\left|E_{\text {exp }, k}^{\prime \prime}-E_{c a l c, k}^{\prime \prime}\right|^{2}}{2 N}}$ 
where $\mathrm{N}$ is the number of data of the spectra, $\mathrm{E}^{\prime}{ }_{\exp }$ and $\mathrm{E}^{\prime}$ calc represent the experimental and calculated values of the storage modulus, $E^{\prime \prime}{ }_{\exp }$ and $E_{\text {calc }}^{\prime \prime}$ those of the loss modulus. The measurement frequency range does not allow observing the relaxation mechanism in its entirety; this explains the zero value of the low frequency storage modulus $\mathrm{E}_{0}$ obtained during the application of the HN model.

The spectrum E' (E") of poly (IBOA-co-IsoBA) at $45^{\circ} \mathrm{C}$ forms a symmetrical and nearly ideal inverted parabola (Fig. 10, Cole-Cole diagram). This form is characteristic of thermorheological amorphous polymers; for partially crystalline polymers, the spectrum $\mathrm{E}^{\prime}$ (E") represents a distorted inverse parabola.

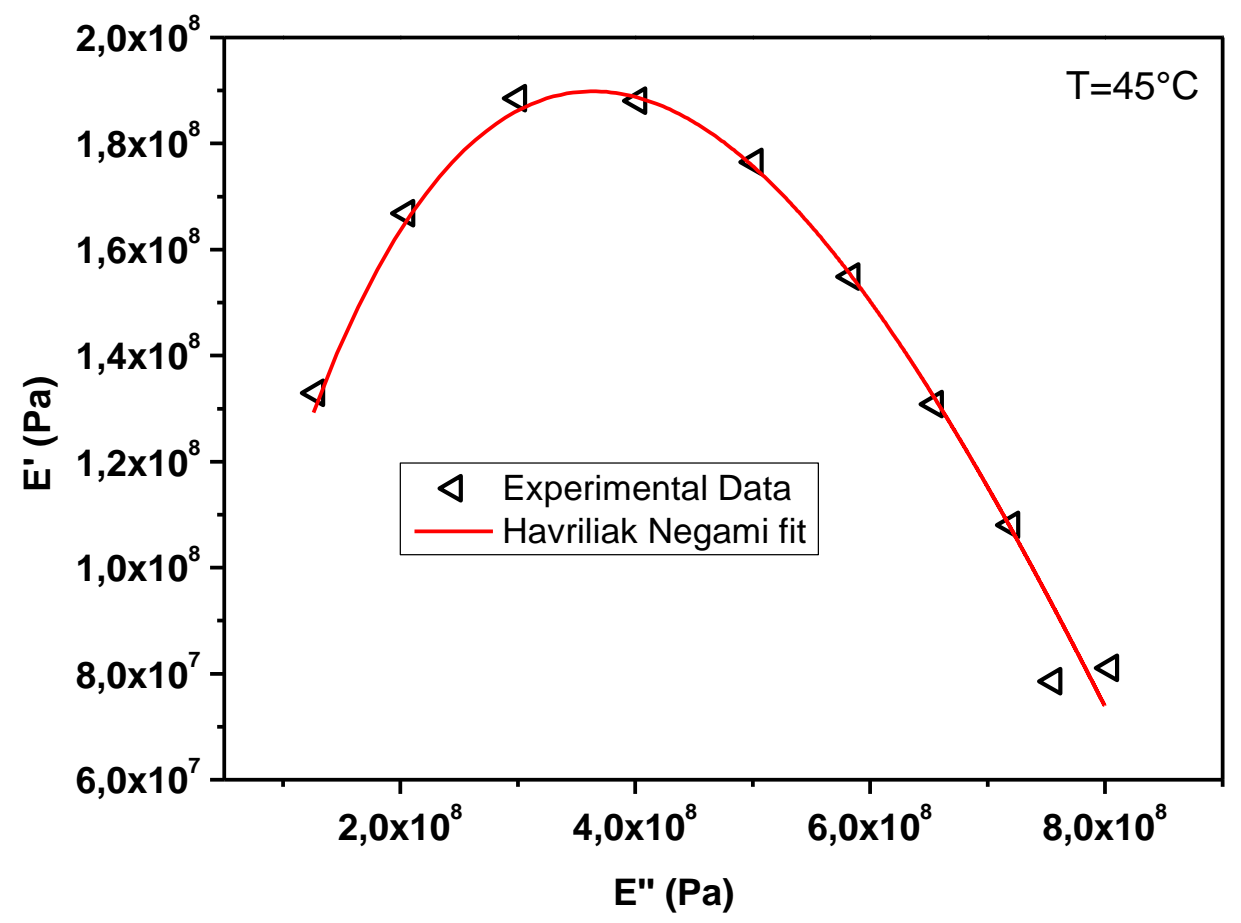

Fig. 10. Evolution of the storage modulus E' of poly(IBOA-co-IsoBA) as a function of its loss modulus E" (Cole-Cole representation), at the temperature $\mathrm{T}=45^{\circ} \mathrm{C}$. The experimental results were modeled using the Havriliak-Negami model. 
The optimization carried out using the Havriliak-Negami model makes it possible to determine the relaxation time $\tau$ of poly (IBOA-co-IsoBA) in the temperature range from 40 to $85^{\circ} \mathrm{C}$. Its evolution as a function of temperature follows the Arrhenius law (Fig. 11):

$\tau=A e^{-\frac{E a}{R T}}$

where A represents a constant, $R$ stands for the universal constant of perfect gases, and $E_{a}$ is the activation energy, which was evaluated as $1.11 \mathrm{~kJ} \mathrm{~mol}^{-1}$.

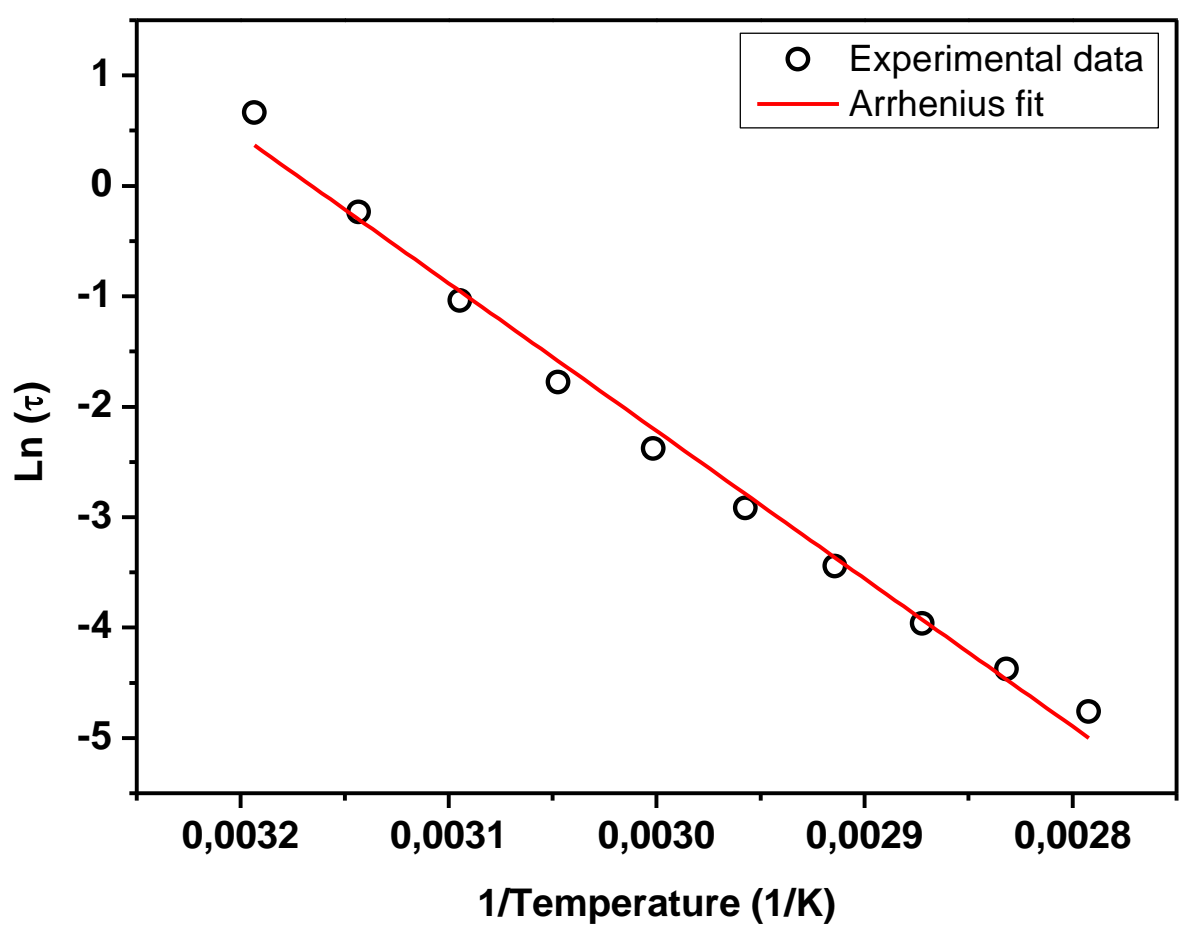

Fig. 11. Evolution of the relaxation time of poly(IBOA-co-IsoBA) depending on the temperature (Arrhenius representation). The experimental results were modeled using the Arrhenius law (Equation (5).

\section{Conclusions}

The thermal and mechanical properties of poly (IBOA-co-IBUA) were studied. The absence of crystallinity effects and the presence of a single glass transition confirm the homogeneous 
and amorphous nature of the elaborated copolymer. The thermal degradation of poly(IBOA) and poly(IBOA-co-IBA) proceeds in two stages, which were related to the chemical structure of the pendant group.

The data from mechanical dynamic analysis reveal the influence of temperature and frequency on storage and loss moduli, and tan delta. The master curve was successfully determined using the WLF equation. The optimization of the mechanical spectra of poly(IBOA-co-IsoBA) was carried out using the Havriliak-Negami model.

\section{Acknowledgements}

This work has been accomplished in the framework of an international research program. The authors gratefully acknowledge the support of the Algerian Ministry of Higher Education and Scientific Research (MESRS), the University of Tlemcen/Algeria, the French Ministry of Higher Education and Research (MENESR), the CNRS, the University and the CROUS of Lille/France.

\section{Data availability}

The raw/processed data required to reproduce these findings cannot be shared at this time as the data also forms part of an ongoing study. 


\section{References}

[1] A. Rudin, P. Choi, Chapter 9 - Copolymerization, in: The Elements of Polymer

Science \& Engineering, Academic Press, 3rd Edition, London, United Kingdom, 2013, Chapter 9 - Copolymerization, pp. 391-425, 10.1016/C2009-1-64286-6

[2] A.J. Scott, A. Penlidis, Copolymerization, in: Reference Module in Chemistry, Molecular Sciences and Chemical Engineering, Elsevier, 2017, 10.1016/B978-0-12$\underline{409547-2.13901-0}$

[3] R. Guerrero-Santos, E. Saldívar-Guerra, J. Bonilla-Cruz, chapter 4, Free Radical Polymerization, in : E. Saldívar-Guerra, E. Vivaldo-Lima (Eds.), Handbook of Polymer Synthesis, Characterization, and Processing, John Wiley \& Sons, Inc., Hoboken, New Jersey, USA, 2013, pp. 65-83, 10.1002/9781118480793.ch4

[4] M.A. Dubé, E. Saldívar-Guerra, I. Zapata-González, chapter 6, Copolymerization, in : E. Saldívar-Guerra, E. Vivaldo-Lima (Eds.), Handbook of Polymer Synthesis, Characterization, and Processing, John Wiley \& Sons, Inc., Hoboken, New Jersey, USA, 2013, pp. 105-125, 10.1002/9781118480793.ch6

[5] Y. Zhou, A.D. Brittain, D. Kong, M. Xiao, Y. Meng, L. Sun, Derivatization of diamondoids for functional applications, J. Mater. Chem. C, 3 (2015), pp. 6947-6961, $\underline{10.1039 / \mathrm{c} 5 \mathrm{tc} 01377 \mathrm{a}}$

[6] J. Brandrup, E.H. Immergut, E.A. Grulke (Eds.), Polymer Handbook, John Wiley \& Sons, Inc., New York, Chichester, Weinheim, Brisbane, Singapore, Toronto, 2003 
[7] M. d. C. López-García, D.J. Beebe, W.C. Crone, Characterization of poly(isobornyl acrylate) as a construction material for microfluidic applications, J. Appl. Polym. Sci., 105 (2007), pp. 1894-1902, 10.1002/app.26195

[8] L. Souza, A. Al-Tabbaa, Microfluidic fabrication of microcapsules tailored for self-healing in cementitious materials, Constr. Build. Mater., 184 (2018), pp. 713-722, $\underline{10.1016 / j . c o n b u i l d m a t .2018 .07 .005}$

[9] F. Ouhib, E. Bugnet, A. Nossov, J.-L. Bonardet, L. Bouteiller, Microporous polyacrylate matrix containing hydrogen bonded nanotubular assemblies, Polymer, 51 (2010), pp. 3360-3364, 10.1016/j.polymer.2010.05.047

[10] C. Zhang, Y. Baia, B. Cheng, W. Liub, Adhesion properties of atactic polypropylene/acrylate blend copolymer and its adhesion mechanism for untreated polypropylene materials, Int. J. Adhes. Adhes., 80 (2018), pp. 7-15, $\underline{\text { 10.1016/j.ijadhadh.2017.09.007 }}$

[11] W. Voit, T. Ware, K. Gall, Radiation crosslinked shape-memory polymers, Polymer, 51 (2010), pp. 3551-3559, 10.1016/j.polymer.2010.05.049

[12] P. Roose, Residual stress in radiation-cured acrylate coatings, React. Funct. Polym., 73 (2013), pp. 323-331, 10.1016/j.reactfunctpolym.2012.05.002

[13] F. Alvarez, J. Colmenero, C.H. Wang, J.L. Xia, G. Fytas, Segmental dynamics in 
bulk poly(isobornyl methacrylate) and its random copolymer with poly(methylmethacrylate) near Tg, Macromolecules, 28 (1995), pp. 6488-6493, $\underline{10.1021 / \mathrm{ma} 00123 \mathrm{a} 015}$

[14] D. Khandelwal, S. Hooda, A.S. Brar, R. Shankar, 1D and 2D NMR studies of isobornyl acrylate - methyl methacrylate copolymers, J. Mol. Struct., 1004 (2011), pp. 121-130, 10.1016/j.molstruc.2011.07.046

[15] D. Khandelwal, S. Hooda, A.S. Brar, R. Shankar, Poly(isobornyl methacrylate-co-methyl acrylate): Synthesis and stereosequence distribution analysis by NMR spectroscopy, J. Polym. Sci. Part A Polym. Chem., 50 (2012), pp. 3350-3362, $\underline{10.1002 / \text { pola. } 26122}$

[16] W. Jakubowski, A. Juhari, A. Best, K. Koynov, T. Pakula, K. Matyjaszewski, Comparison of thermomechanical properties of statistical, gradient and block copolymers of isobornyl acrylate and n-butyl acrylate with various acrylate homopolymers, Polymer (London), $49 \quad$ (2008), $\quad$ pp. 1567-1578, $\underline{10.1016 / j . p o l y m e r .2008 .01 .047}$

[17] I. Ward, D. Hadley, An introduction to the mechanical properties of solid polymers, John Wiley \& Sons, Chichester, United Kingdom, 1993

[18] J.-P. Pascault, H. Sautereau, J. Verdu, R.J.J. Williams, Thermosetting polymers, Marcel Dekker Inc., New York, Basel, 2002 
[19] H.E.H. Meijer, L.E. Govaert, Mechanical performance of polymer systems: the relation between structure and properties, Prog. Polym. Sci., 30 (2005), pp. 915-938, $\underline{10.1016 / j . p r o g p o l y m s c i .2005 .06 .009 ~}$

[20] K.P. Menard, N. Menard, Dynamic Mechanical Analysis, in: Encyclopedia of Analytical Chemistry: Applications, Theory and Instrumentation, John Wiley \& Sons, Inc., Hoboken, New Jersey, USA, 2017, 10.1002/9780470027318.a2007.pub3

[21] K.S. Cole, R.H. Cole, Dispersion and absorption in dielectrics I. Alternating current characteristics, J. Chem. Phys., 9 (1941), pp. 341-351, 10.1063/1.1750906

[22] D.W. Davidson, R.H. Cole, Dielectric relaxation in glycerol, propylene glycol, and n-propanol, J. Chem. Phys., 19 (1951), pp. 1484-1490, 10.1063/1.1748105

[23] S. Havriliak, S. Negami, A complex plane analysis of $\alpha$-dispersions in some polymer systems, J. Polym. Sci. Part C Polym. Symp., 14 (1966), pp. 99-117, $\underline{10.1002 / \text { polc. } 5070140111}$

[24] G. Williams, D.C. Watts, Non-symmetrical dielectric relaxation behaviour arising from a simple empirical decay function, Trans. Faraday Soc., 66 (1970), pp. 80-85, $\underline{10.1039 / \mathrm{TF} 9706600080 .}$.

[25] J.S. Medina, R. Prosmiti, P. Villarreal, G. Delgado-Barrio, J. V. Alemán, Frequency domain description of Kohlrausch response through a pair of Havriliak-Negami-type functions: An analysis of functional proximity, Phys. Rev. E 84, 066703 (2011), 
[26] M. Bouchakour, Y. Derouiche, Z. Bouberka, C. Beyens, L. Mechernene, F. Riahi, U. Maschke, Optical properties of electron beam- and UV-cured polypropyleneglycoldiacrylate/liquid crystal E7 systems, Liq. Cryst., 42 (2015), pp. 1527 $1536, \underline{10.1080 / 02678292.2015 .1044579}$

[27] T. Bouchaour, F. Benmouna, X. Coqueret, M. Benmouna, U. Maschke, Swelling of crosslinked poly(acrylates) in isotropic and anisotropic solvents, J. Appl. Polym. Sci., 91 (2004), pp. 1-9, 10.1002/app.12608

[28] D. Bikiaris, J. Prinos, M. Botev, C. Betchev, C. Panayiotou, Blends of polymers with similar glass transition temperatures: A DMTA and DSC study, J. Appl. Polym. Sci., 93 (2004), pp. 726-735, 10.1002/app.20531

[29] J.A. Ors, D.M. La Perriere, Thermogravimetric profile of decomposition of acrylate systems based on bornyl acrylate monomers, Polymer, 27 (1986), pp. 1999-2002, $\underline{10.1016 / 0032-3861(86) 90197-7}$

[30] S. Ozlem, E. Aslan-Gürel, R.M. Rossi, J. Hacaloglu, Thermal degradation of poly(isobornyl acrylate) and its copolymer with poly(methyl methacrylate) via pyrolysis mass spectrometry, J. Anal. Appl. Pyrolysis, 100 (2013), pp. 17-25, $\underline{10.1016 / j . j a a p .2012 .10 .024}$

[31] A. Matsumoto, K. Mizuta, O. Takayuki, Synthesis and thermal properties of 
poly(cycloalkyl methacrylate)s bearing bridged- and fused-ring structures, J. Polym. Sci., 31 (1993), pp. 2531-2539, 10.1002/pola.1993.080311014

[32] J. Qu, J. Cheng, Z. Wang, X. Han, M. Zhao, Synthesis, thermal and optical properties of crosslinked poly(isobornyl methacrylate-co-butyl acrylate) copolymer films, Opt. Mater. (Amst)., 36 (2014) pp. 804-808, 10.1016/j.optmat.2013.11.030

[33] K.P. Menard, Dynamic Mechanical Analysis: A Practical Introduction, CRC Press, Taylor \& Francis group, Boca Raton; London; New York; $2^{\text {nd }}$ Edition, 2008

[34] Y. Bai, L. Jin, Characterization of frequency-dependent glass transition temperature by Vogel-Fulcher relationship, J. Phys. D. Appl. Phys., 41 (2008), 152008, $\underline{10.1088 / 0022-3727 / 41 / 15 / 152008}$

[35] T. Ware, D. Simon, D.E. Arreaga-Salas, J. Reeder, R. Rennaker, E.W. Keefer, W. Voit, Fabrication of responsive, softening neural interfaces, Adv. Funct. Mater., 22 (2012), pp. $3470-3479, \underline{10.1002 / \mathrm{adfm} .201200200}$

[36] M.L. Williams, R.F. Landel, J.D. Ferry, The temperature dependence of relaxation mechanisms in amorphous polymers and other glass-forming liquids, J. Am. Chem. Soc., 77 (1955), pp. 3701-3707, 10.1021/ja01619a008 